\title{
O ENSINO DA LEITURA COMO PROCESSO DA PRÁTICA PEDAGÓGICA
}

\section{THE TEACHING OF READING AS A PROCESS OF PEDAGOGICAL PRACTICE}

José Aroldo da Silva*

Resumo: As práticas de leitura a serem adotadas pelos professores da Educação Infantil, mesmo diante da carência de material de leitura, devem ser encaminhadas de modo que venham a favorecer a formação de cidadãos críticos e conscientes, uma vez que se faz necessário explorar o conhecimento de mundo do aluno, priorizando a contextualização dos textos com a realidade vivida pelo educando.

Palavras-chave: Leitura. Gêneros Textuais. Ensino.

Resumen: The reading practices to be adopted by teachers who work at Childhood Education (Elementary Level), even in face of the lack of reading materials, should be approached so that they contribute to the development of critical and conscious citizens, as it is necessary to explore students' previous world knowledge, in addition to considering the contexts of the texts and students' reality.

KEYWorDs: Reading. Textual genres. Education.

INTRODUÇÃO

Este trabalho aborda o ensino da leitura como processo da prática pedagógica na Educação Infantil, visando o desenvolvimento da aprendizagem das crianças para a formação de leitores críticos e conscientes do papel a desempenhar na sociedade. O trabalho foi motivado pelas dificuldades que professores de Educação Infantil encontram para trabalhar a leitura em sala de aula, constatada a partir da prática cotidiana com os aprendizes de leitura.

Sabe-se que as crianças antes de entrarem na escola já têm contato com textos que lhes são lidos, sendo importante que a escola desenvolva projetos que trabalhem com leitura, considerando esse conhecimento prévio de leitura que a sua clientela tem. A escola, para trabalhar a leitura, deve partir do conhecimento de

"Mestre em Ciências da Sociedade pela Universidade Estadual da Paraíba (UEPB). E-mail: carnoio@ig.com.br 
leitura que a criança traz dentro de si, utilizando os diferentes tipos de textos, tais como jornais, revistas, histórias em quadrinhos, livros infantis, embalagens, bulas, etc., os quais fazem parte do meio social em que o educando está inserido.

$O$ presente trabalho encontra-se dividido em dois tópicos. No primeiro, intitulado Educação e Alfabetização, realiza-se uma discussão sobre educação e alfabetização no contexto das práticas de leitura.

No segundo, que tem como título Leitura no Brasil, apresenta-se uma série de elementos sobre a leitura no Brasil, trazendo a abordagem dos Parâmetros Curriculares Nacionais sobre o tema leitura e enfatizando os gêneros textuais. Para terminar, são feitas Considerações Finais, em que se apresentam as conclusões a que se chegou após a pesquisa bibliográfica sobre leitura.

\section{EduCAÇão E ALFABETIZAÇ̃̃o}

A educação escolar difere das demais formas educacionais por ser institucionalizada. A escola tem horários e estabelece critérios para agrupamentos de alunos e tem profissionais realizando tarefas diferenciadas como: professor, diretor, supervisor escolar, e outros.

Segundo Brandão (2003, p. 7):

Ninguém escapa da educação. Em casa, na rua, na igreja, ou na escola, de um modo ou de muitos todos nós envolvemos pedaços da vida com ela: para aprender, para ensinar, para aprender-e-ensinar. Para saber, para fazer, para ser ou pra conviver, todos os dias misturamos a vida com a educação.

Nesta perspectiva apresentada por Brandão, a educação não acontece apenas no ambiente escolar, ou seja, de forma institucionalizada, podendo a educação acontecer nos mais diversos ambientes. Daí Brandão (op. cit., p. 13) afirmar que:

A educação existe onde não há a escola e por toda parte pode haver redes e estruturas sociais de transferência de saber de uma geração a outra, onde ainda não foi sequer criada a sombra de algum modelo de ensino formal e centralizado. Porque a educação aprende com o homem a continuar o trabalho da vida.

Para se tratar da questão da educação dentro de um conceito que envolva o indivíduo em suas diferentes formas de convivência com o mundo no qual está inserido, se faz necessário examinar a legislação brasileira sobre educação, começando pela nova Lei de Diretrizes e Bases da Educação Nacional - LDBEN, Lei $n^{\circ}$ 9.394/96, que se inicia apresentando uma definição de educação afirmando que:

A educação abrange os processos formativos que se desenvolvem na vida familiar, na convivência humana, no trabalho, nas instituições de ensino e pesquisa, nos movimentos sociais e organizações da sociedade civil e nas manifestações culturais. (LDBEN/1996, art. 1. ${ }^{\circ}$, p. 4).

Como se pode observar, a educação não é realizada apenas nas instituições de 
ensino, mas envolve todo o universo ocupado pelo homem na sua vida cotidiana. Partindo desta afirmação, vê-se que a educação escolar não está desvinculada da totalidade que envolve o indivíduo.

Todavia, não existe sociedade sem educação, nem educação sem sociedade, ou seja, a prática educativa, fenômeno social e universal, é uma atividade do homem, necessária para existência e funcionamento de todas as sociedades. Sabedor disto, o legislador, na formatação da Lei de Diretrizes e Bases da Educação Nacional, referindo-se à educação, escreve no Art. $1^{\circ}, \$ 2 .^{\circ}$ que "A educação escolar deverá vincular-se ao mundo do trabalho e à prática social".

Em seu título II - Dos princípios e fins da educação nacional, a Lei n 9.394/96 apresenta as finalidades da educação, que tem como objetivo a formação educacional do cidadão: "A educação, dever da família e do Estado, inspirada nos princípios de liberdade e nos ideais de solidariedade humana, tem por finalidade o pleno desenvolvimento do educando, seu preparo para a cidadania e sua qualificação para o trabalho".

Dentro desse preparo para a cidadania, não se pode esquecer da questão da leitura, vislumbrando-a como um instrumento capaz de contribuir decisivamente para a formação do cidadão consciente de seu papel na sociedade. Tratando da importância da leitura para a vida intelectual do estudante, Lajolo e Zilberman (1996, p. 7) dizem:

Com efeito, a leitura, se é estimulada e exercitada com maior atenção pelos professores de língua e literatura, intervém em todos os setores intelectu- ais que dependem, para sua difusão, do livro, repercutindo especialmente na manifestação escrita e oral do estudante, isto é, na organização formal de seu raciocínio e expressão.

Este processo para a formação de leitores se faz necessário que seja construído na escola, já a partir da alfabetização do indivíduo, a qual é assim definida por Cagliari (1997, p. 166):

[...] alfabetizar é tornar apto para determinada tarefa ou atividade para que os alunos representem graficamente a fala pela combinação das letras do alfabeto. Escrever e ler são atividades que a escola ensina quase ao mesmo tempo, porém, é dado mais ênfase a escrita.

O aluno é mais explorado em relação ao que escreve, ficando a leitura um pouco de lado. O que acontece é que a escola, ao avaliar o aluno, usa a escrita como critério, pois é bem mais fácil "achar" o certo e o errado na escrita do que na leitura. Nesse caso, a escrita tem poder maior por conta da avaliação escolar.

A tendência escolar em privilegiar a escrita em detrimento da leitura não é uma atividade razoável quando se pretende formar um bom aluno leitor. Na verdade, a leitura, no começo da vida escolar, é tão importante quanto à produção livre de um texto. "Nessa perspectiva é essencial a vinculação da escola com as questões sociais e com os valores democráticos, não só do ponto de vista da seleção e tratamento das leituras, como também da própria organização escolar." (CAGLIARI, op. cit. p. 48). 
Nos dias de hoje, devido à evolução e à modernidade, pode se dizer que é mais importante ler do que escrever. Como evidência disto, sabe-se que pessoas que vivem nas cidades precisam saber ler, ou pelo menos decifrar códigos e ler através de figuras como: rótulos, placas de ônibus, números, documentos, etiquetas, etc. Sendo assim, nos nossos dias podemos encontrar pessoas alfabetizadas que vivem quase sem escrever.

Mediante o aspecto anterior, podemos admitir que se ensina não só a ler textos contidos nos livros didáticos da escola, mas também a ler aqueles que estão dispostos no amplo meio social de cada indivíduo.

Consideramos a importância da leitura, reconhecemos que se aprende neste conhecimento não só para ler, mas também reconhecer o mundo, treinar pronúncia e viajar numa dimensão, em que se misturam realidade e fantasia. Nesta ótica de aprendizagem, é importante reconhecer que o professor deve fazer da leitura uma atividade prazerosa, levando o conhecimento e dando oportunidade para que a criança se expresse de maneira espontânea, estimulando assim sua formação de leitor. Nessa perspectiva, sugerimos que é preciso repensar esse procedimento em relação à escrita e à leitura, desde o início do processo de alfabetização. Uma criança que aprende a ler toma velocidade no aprendizado da primeira série, um aluno que não lê, aprenderá o resto com dificuldade e pode passar a ter uma relação delicada com a escrita, não entendendo muito bem o que está acontecendo, nem como funciona.
O objetivo da escrita é a leitura, mas quem vai escrever só é capaz de fazê-lo se souber ler o que escreve, portanto a leitura é uma habilidade que precede a própria escrita. Por que, então, não começar a ensinar a escrever e a ler, dando mais ênfase à leitura? E, quando se fala em leitura, é para avaliar a capacidade de decifração de letras da escrita. Ao iniciar o processo de leitura, a escola costuma voltar-se ao be-a-bá e às famílias silábicas, podendo gerar problemas para o aluno. Reconhecer as famílias silábicas faz do processo de decifração não apenas uma leitura, mas é um estágio inicial da leitura.

O professor, então, deve dar tempo para que o aluno vença todas as dificuldades e obstáculos que existem na sua vida e no seu caminho. Quando a escola insiste ou pressiona o aluno, ele não consegue raciocinar, e isso não é correto, nem com o aluno nem tão pouco com o professor. (CAGLIARI, op. cit. p. 56).

A respeito do aspecto semântico, as crianças conhecem um vasto número de palavras e conseguem descobrir o significado de outras pelo contexto em que se encontram. Quando desconhecem algumas palavras e necessitam saber, elas questionam o significado. Não é necessário explicar o significado de todas as palavras de um texto antes que a criança o leia, deve-se deixar que a criança leia primeiro, para depois selecionar suas dúvidas de acordo com seus questionamentos, e então a criança deve ser estimulada a perguntar e a entender os significados das palavras dentro do contexto em que estão inseridas. 
Faz-se necessário também que os alunos saibam que um texto pode ser lido de várias maneiras e com pronúncias diversas. A escola deve mostrar aos alunos que existem algumas expectativas com relação à fala de seus membros e, consequentemente, uma leitura no dialeto padrão é um prestígio no meio social e uma leitura com uma pronúncia bem elaborada poderá ser objeto de risco, portanto, é indispensável ensinar ao aluno, o que é próprio da linguagem e o que é próprio do uso que a sociedade faz da linguagem.

\section{LEITURA NO BRASIL}

História da Leitura no BRAsil

Inicialmente, teríamos uma oferta muito restrita de leitura na escola. Restrita, em primeiro lugar, tendo em vista os objetos de leitura. Das chamadas "cartas de fora" - documentos ou cartas manuscritos - usadas para ensinar a ler, teríamos assistido a uma progressiva introdução e diversificação do livro didático, contrabalançada, mais recentemente, pelas tentativas de tornar presentes, em sala de aula, objetos escritos tal como circulam socialmente - jornais, revistas, livros, rótulos e assim por diante.

Em segundo lugar, as oportunidades de leitura escolares teriam se ampliado, tendo em vista a própria natureza das práticas escolares de leitura. Mais inicialmente, formar leitores parece ter significado não propriamente desenvolver as competências e usos da leitura, mas antes ensinar outras coisas através da leitura escolar. É o que sugere a análise dos livros didáticos mais utili- zados no Brasil no século XIX e nas décadas iniciais do século XX.

O que se buscava, quando se formavam leitores, poderia ser - como no caso dos livros de Abílio César Borges e de Felisberto de Carvalho - a transmissão de conteúdos instrutivos, em geral das áreas de ensino que terminaram por se consolidar na tradição escolar brasileira: geografia, história, ciências; poderia ser - como no caso dos livros de Olavo Bilac e da maior parte dos livros brasileiros de então - a transmissão de regras e modelos de comportamento, de uma imagem idealizada da criança, centrada em aspectos morais e ideológicos; poderia, enfim, ser a transmissão apenas das habilidades básicas de leitura e escrita e das regras ortográficas do português.

O modo pelo qual se lia parece também ter sido, inicialmente, um modo muito restrito. A leitura favorecida pelo modelo do "dar e tomar lição" parece ser aquela em voz alta, lenta e muito associada à memorização do texto.

Na virada deste milênio, a qualidade e a quantidade da oferta de leitura deixa muito a desejar. Muito do passado do ensino de leitura, portanto, vive no presente. Se isso é verdade, muito do ensino da leitura do presente vive, de algum modo, no passado.

\section{Os Parâmetros Curriculares Nacionais E A Leitura}

Os Parâmetros Curriculares Nacionais (PCNs) têm por objetivo auxiliar os profissionais de educação no processo de ensino-aprendizagem, fazendo com que as crianças possam dominar os conhecimentos 
necessários à sua formação de cidadãos plenamente conscientes do seu papel na sociedade. Tratando da leitura no tópico Aprendizado inicial da leitura, os PCNs afirmam ser preciso a superação de algumas concepções sobre o aprendizado da leitura.

O professor, principalmente, o de língua portuguesa, precisa entender que ler não é simplesmente decodificar. Superando esta concepção, a escola deixará de formar uma quantidade enorme de leitores que são capazes apenas de decodificar o texto, mas que apresentam uma enorme dificuldade quando tentam compreender aquilo que leem.

Os Parâmetros Curriculares Nacionais sugerem que não se pode ensinar as crianças a ler a partir de práticas centradas no processo de decodificação do texto, afirmando que:

é preciso oferecer aos alunos inúmeras oportunidades de aprenderem a ler usando procedimentos que os bons leitores utilizam. É preciso que antecipem, que façam inferências a partir do contexto ou do conhecimento prévio que possuem, que verifiquem suas suposições - tanto em relação à escrita, propriamente, quanto ao significado (p.42).

Os PCNs vão mais adiante quando afirmam que os materiais produzidos exclusivamente para ensinar a ler não são bons, têm servido apenas para ensinar a decodificar, contribuindo para que o aluno construa uma visão empobrecida da leitura (p. 42). Sugerem que, para que a criança aprenda a ler, se faz necessário que o professor o coloque em contato com uma diversidade de textos escritos, afirmando que esta atitude contribuiria para o aprendizado da leitura.

Para aprender a ler, portanto, é preciso interagir com a diversidade de textos escritos, testemunhar a utilização que os já leitores fazem deles e participar de atos de leitura de fato; é preciso negociar o conhecimento que já se teme o que é apresentado pelo texto, o que está atrás e diante dos olhos, recebendo incentivo e ajuda de leitores experientes (p. 42).

Outra concepção que os Parâmetros Curriculares Nacionais sugerem é a superação do mito da interpretação única, ou seja, uma interpretação autorizada que não permite que o aluno busque a diversidade de significadas que o texto apresenta. Falando da necessidade da superação da interpretação única, os PCNs afirmam:

O significado, no entanto, constrói-se pelo esforço de interpretação do leitor, a partir não só do que está escrito, mas do conhecimento que traz para o texto. É necessário que o professor tente compreender o que há por trás dos diferentes sentidos atribuídos pelos alunos aos textos: às vezes é porque o autor 'jogou com as palavras' para provocar interpretações múltiplas; às vezes é porque o texto é difícil e confuso; às vezes é porque o leitor tem pouco conhecimento sobre o assunto tratado e, a despeito do seu esforço, compreende mal (p. 43).

O professor deve levar em consideração a interpretação produzida pelo aluno, uma vez que para a compreensão do texto 
o aluno envolve o conhecimento prévio e o conhecimento de mundo que traz para o ambiente escolar.

Para a formação de leitores os Parâmetros Curriculares Nacionais (p. 58) informam que algumas condições se fazem necessárias e o documento elenca as seguintes:

a) dispor de uma boa biblioteca;

b) dispor, nos ciclos iniciais, de um acervo de classe com livros e outros materiais de leitura;

c) organizar momentos de leitura livre em que o professor também leia;

d) planejar as atividades diárias garantindo que as de leitura tenham a mesma importância que as demais;

e) possibilitar aos alunos a escolha de suas leituras;

f) possibilitar aos alunos o empréstimo de livros na escola;

g) construir na escola uma política de formação de leitores na qual todos possam contribuir com sugestões para desenvolver uma prática constante de leitura que envolva o conjunto da unidade escolar.

As sugestões oferecidas pelos Parâmetros Curriculares Nacionais para as atividades voltadas à formação de leitores na escola iniciam-se com o aspecto material da leitura que seria a disposição de uma biblioteca na unidade escolar e encerram-se com uma alusão à mudança de mentalidade, quando requer que a escola construa uma política de formação de leitores, a partir da contri- buição de todos os atores envolvidos no processo educacional no ambiente escolar.

\section{Gêneros Textuais}

Para realizar o trabalho com leitura é necessário que o professor apresente ao aluno a diversidade de textos que circulam na sociedade. São textos que vão da lista de compra do supermercado até a correspondência eletrônica realizada no computador por meio do e-mail. Em uma sociedade onde a cada dia se requer mais conhecimento, o indivíduo, para exercer plenamente a sua cidadania, deve dominar a leitura para poder se inserir nas discussões e transformações constantes da sociedade.

A escola, ainda apegada aos tempos passados, na maioria das vezes, acha mais conveniente oferecer aos seus educandos a leitura apenas dos livros didáticos, cheios de ideologias e quase sempre patrocinados pela classe dominante, em vez de proporcionar o encontro com uma leitura transformadora, a leitura que venha libertar o indivíduo das correntes ideológicas e das amarras do sistema capitalista.

Tratando dos objetivos e estratégias para o ensino de língua portuguesa, principalmente no segundo ciclo, os Parâmetros Curriculares Nacionais sustentam a necessidade da apresentação dos diversos gêneros discursivos aos alunos, afirmando que:

No que se refere aos aspectos discursivos, amplia-se o trabalho realizado anteriormente e, pela inclusão de novos gêneros de textos, aprofunda-se $o$ tratamento de conteúdos referentes à organização 
dos elementos específicos desses diferentes gêneros, do tipo de relação que se estabelece entre eles, dos recursos coesivos utilizados, léxico adequado, etc. (PCN, 2001, p. 125-126).

Precisa-se desmistificar a ideia de que a leitura é um bem apenas da classe dominante e que a classe trabalhadora deve adquiri-la apenas para lidar com algumas técnicas voltadas para o trabalho. Querendo mudar essa realidade, o educador deve resgatar, no cotidiano escolar, uma prática de leitura inerente ao discurso das crianças, ou seja, que proporcione meios para que a leitura no espaço da sala de aula seja uma ponte para uma transformação do meio onde estão inseridos, bem como possam ter uma visão mais clara do mundo que está ao seu redor.

Os gêneros textuais estão diretamente ligados aos diversos processos sofridos pelo homem durante vários séculos, relacionados às várias diferenças socioculturais, esses gêneros passaram por várias transformações, que acabaram por fim sendo fatores determinantes para a diversidade textual.

Para minimizar as necessidades existentes durante o uso da oralidade, que até então era a única forma de comunicação, o que limitava a vida social, foi necessário a invenção da escrita, que teve por fim sua explosão no período em que a Europa encontrava-se em fase de expansão o que acarretou inúmeras consequências positivas, resumindo-se à ampliação expressiva dos meios de comunicação.

Esses gêneros são fenômenos mutáveis, o que condiciona o desaparecimento ou o reaparecimento das diversas formas apresentáveis.

O aparecimento dos novos tipos de gêneros foi propiciado por uma divulgação maior através dos meios de comunicação, tais como TV, rádio, revista, jornal, Internet, editoriais, notícias, e-mails, aulas virtuais, telegramas, telemensagens.

Por isso, o tipo textual é muito claro, pois se trata do aspecto teórico e terminológico, ou seja, ele se classifica pelo conjunto limitado de categorias teóricas, determinadas por aspectos lexicais, sintáticos, relações lógicas, tempo verbal e nomes teóricos dos tipos: narrativa, argumentação, descrição, injunção e exposição.

Também encaixada nos gêneros textuais, estão os domínios discursivos, que é uma forma de aperfeiçoar as atividades humanas, podendo ser um discurso jurídico, jornalístico, religioso, etc., que darão origem a vários gêneros.

Mesmo que não muito visível, existem diferenças entre o texto e o discurso, podendo dizer que o texto é a forma materializada em algum gênero textual, enquanto o discurso é a manifestação de alguma ideia ou opinião.

Porém, alguns livros didáticos ainda confundem e acabam errando ao designar tipo de texto quando na verdade é gênero textual.

Ao escrever algum texto, dependendo de quem for o destinatário, isto é que definirá o tipo de texto e, assim sendo, apresentados de formas heterogêneas, dando a um gênero dois ou mais tipos.

Um gênero, quando apresenta uma outra função, será chamado de intertextua- 
lidade inter-gêneros, e quando apresenta vários tipos textuais, será chamado de heterogeneidade tipológica.

Os gêneros textuais são designados através de modalidades do cotidiano, distribuindo-se em todas as formas e todos os contextos, sendo transmitidos oralmente mais são concebidos na forma escrita e o inverso.

Percebe-se que há inadequação de normas sociais relativas aos gêneros textuais, $\mathrm{e}$ que para tanto a adequação tipológica deve levar em conta a formação cultural, social e econômica.

São apresentados alguns aspectos para a presença dos diferentes exemplos e apresentações dos textos, tais como a natureza da informação ou de conteúdo veiculado que é o caráter sociocultural, o nível de linguagem, desde o formal até o informal, o tipo de situação em que o gênero se situa, que é o local em que será veiculado; se as relações entre os participantes são conhecidas ou desconhecidas, e a natureza dos objetivos das atividades desenvolvidas, podendo sofrer alterações dependendo da finalidade da comunicação.

O professor tem um papel fundamental de incentivar os alunos quanto aos aspectos relacionados com as questões gramaticais e de organização do texto.

A importância de se entender essas questões de linguagem relacionada aos gêneros textuais é de fundamental importância, porque isso vai permitir conhecer a própria dinâmica da comunicação social no seio de uma comunidade, pois se trata de um fenômeno construído historicamente e socialmente em cada meio social. Além do que, vivemos numa sociedade onde a comunicação é a mola mestra dos organismos sociais e dos relacionamentos humanos e isto é verificado nos sermões, na liturgia, numa propaganda, numa entrevista, em reuniões, ou seja, em todos os lugares ocupados por seres humanos; em casa, na igreja, na escola, na rua, lojas, na TV, anúncios, repartições públicas, em todos esses ambientes o homem vai está utilizando gêneros textuais os mais variados.

No tocante ao ambiente escolar, o conhecimento e o domínio dos gêneros textuais é imprescindível para que o aluno possa entender e identificar os eventos linguísticos e, assim, poder produzir textos a partir das características que cada gênero possui; lembrando-nos que, numa escola, o discurso do professor é um gênero textual oral falado a partir de um escrito que pode ser um artigo, um texto jornalístico, uma crônica, um romance literário. Portanto, saber lidar com os gêneros textuais é principalmente saber entender a própria língua e o seu uso no seu dia a dia, bem como poder transmitir no mundo da linguagem, da comunicação, compreendendo o seu teor comunicativo, como foi construído e a quem se destina. Vale salientar que esse conhecimento também significa inter-relacionar os vários gêneros apresentados e construídos ao longo da história, desde o texto escrito à TV e à Internet.

O educador, no exercício de seu trabalho, deve mudar a ideia, que há muito tempo esteve e ainda está presente, na maior parte da população, de que a leitura é um instru- 
mento para alcançar melhores condições subir na vida e estar apto para o mercador de trabalho; muitos veem a leitura com esse único fim, o que os torna pessoas fáceis para os dominantes.

A escola, no seu cotidiano, deve preocupar-se em desenvolver formas de leitura na visão de um mundo real, isto é, oportunizar a seus educandos entrarem em contato com textos significativos e sempre procurando articulá-los com a vida real de cada um. O professor, peça fundamental na educação de um povo, não pode acomodarse e utilizar, em seu espaço de trabalho, leituras descontextualizadas do dia a dia dos educandos, pois, agindo assim, estará contribuindo para a construção de um povo sem esperança, sem visão crítica e que desvaloriza sua própria cultura.

Tendo consciência de que a leitura é uma ação que pode produzir sentidos para quem a pratica e que o sentido não está na mensagem escrita, mas, sim, na interpretação que o leitor faz, é de grande importância proporcionar aos alunos o contato com os diferentes tipos de textos, os chamados textos do "mundo", para que eles possam tornar-se leitores competentes.

Ensinar a nossos educandos a libertarem-se do livro didático e partirem para a leitura dos diversos gêneros literários é uma tarefa que cabe única e exclusivamente aos educadores. Responsabilidade ainda maior é fazer com que o aluno entenda a mensagem que cada leitura traz, mas sabendo que a leitura abre um novo mundo pra os educandos. Cabe aos educadores incentivar a prática da leitura, buscando meios para que os educandos compreendam a importância e aprendam a diferenciar a diversidade textual que existe e o discurso que cada um apresenta.

\section{Consideracões FinAIS}

Sabemos que as crianças, aprendizes da leitura, antes de entrarem na escola já têm contato com textos que lhes são lidos, sendo importante que a escola, ao recebê-los, desenvolva projetos que trabalhem com leitura, levando em considerando o conhecimento prévio de leitura que a criança possui.

Para o aprendizado da leitura, segundo os Parâmetros Curriculares Nacionais e os autores que fundamentaram as argumentações teóricas deste trabalho, é necessário que os educandos tenham contato com os mais variados tipos de textos escritos.

A leitura deve ser vista como um conjunto de comportamentos que se regem por processos cognitivos armazenados na memória do indivíduo, os quais afloram durante o contexto da atividade de leitura.

Sendo assim, concluiu-se que as práticas de leitura a serem adotadas pelos professores da Educação Infantil, mesmo diante da carência de material de leitura, devem ser encaminhadas de modo que venham a favorecer a formação de cidadãos críticos e conscientes, uma vez que se faz necessário explorar o conhecimento de mundo do aluno, priorizando a contextualização dos textos com a realidade vivida pelo educando. 
REFERÊNCIAS

BRANDÃO, Carlos Rodrigues. 0 que é educação? 12. ed. São Paulo: Brasiliense, 2003. BRASIL. Lei de Diretrizes e Bases da Educação Nacional. Brasília: Senado, 1997.

BRASIL. Parâmetros Curriculares Nacionais. 3. ed. Brasília: MEC, 2001.

CAGLIARI, Luiz Carlos. Alfabetização e linguística: pensamento e ação no magistério. 10. ed. São Paulo: Scipione, 1997.

LAJOLO, Marisa; ZILBERMAN, Regina. A formação da leitura no Brasil. São Paulo: Ática, 1996.

Recebido para publicação em 20 ago. 2012. Aceito para publicação em 25 jan. 2013. 